\title{
An Investigation into the Adoption of Digital Design Software in the Curriculum of Interior Design
}

\author{
Sadia Farooq ${ }^{1}$, Mohammad Arif Kamal, ${ }^{2, *}$ \\ ${ }^{1}$ Department of Family and Consumer Sciences, University of Home Economics, Pakistan \\ ${ }^{2}$ Architecture Section, Aligarh Muslim University, India
}

Received July 30, 2020; Revised September 10, 2020; Accepted September 30, 2020

\begin{abstract}
Cite This Paper in the following Citation Styles
(a): [1] Sadia Farooq, Mohammad Arif Kamal, "An Investigation into Adoption of Digital Design Software in the Education of Interior Design," Universal Journal of Educational Research, Vol. 8, No. 11B, pp. 6256 - 6262, 2020. DOI: 10.13189/ujer.2020.082264.
\end{abstract}

(b): Sadia Farooq, Mohammad Arif Kamal (2020). An Investigation into Adoption of Digital Design Software in the Education of Interior Design. Universal Journal of Educational Research, 8(11B), 6256 - 6262. DOI: 10.13189/ujer.2020.082264

Copyright $\odot 2020$ by authors, all rights reserved. Authors agree that this article remains permanently open access under the terms of the Creative Commons Attribution License 4.0 International License

\begin{abstract}
The internet, progressed technology tools and software are prominent evidence of the digital revolution that has influenced the methods of teaching, especially in interior and product design courses. The revolution is the need to fully equip students of design institutions with Digital Design Software (DDS), but the hand drawing skills (HDS) are also required to understand the basics of drawing. The objective of the research is to evaluate students' preferences regarding hand drawing and DDS, their command on DDS, and professional demand of DDS after academics. The interior design course is about drawing and designing ideas. It seems to be a contradiction when involving both hands and digital skills. This is a quantitative research in which structured questionnaire was asked to the final year students in three institutes of Interior Design. These institutes are selected, since the students are skilled in using Auto CAD, 3D Max, Adobe Photoshop, Sketch-up. The questionnaire used a Likert ranging from (1-5), 1 strongly agree, 2 agree, 3 neutral, 4 disagree and 5 strongly disagree. There were 90 respondents, the results show that most of the students were comfortable to use DDS and they consider DDS more convenient than hand drawing. The students consider DDS more effective than Hand Drawing Skill (HDS) and they know how to accurately use DDS in interior design. The tasks can be completed speedily, easily, and as handy as can be presented any time anywhere and finally making the students more market-oriented in their practical field after academics.
\end{abstract}

Keywords Digital Design, Computer Software, Interior Design, Creativity, Education

\section{Introduction}

Over the latest couple of decades, dynamic progression in the subject of Information and Technology has influenced our customary daily life [1]. The present youngsters are the originals of the digital and advanced age. The intensive application of computers and information \& communication technology (ICT) in Architecture has challenged us to re-think common practices in architectural education. Many studies and researches have been done on the use and integration of digital technology in architectural and Interior design education which are majorly concerned with enhancing communication amongst designers or would-be Architects [2]. The study by Abdullah, et al have shown that it is now the need to rely mostly on digital software almost in all the fields. In this way, the improvement of such digital tools over an unusually short time and their advancement and amendment has an obvious impact on instructive parts of educational plans in design fields [3]. The utilization of digital design software (DDS) is turning into the most significant need in interior design now, which gives less time, low cost, ready to accelerate proposition or basic drawings, and without the use of paper, with feasibility to 
present anytime at anyplace [4].

Presently all students ought to investigate and use digital software as it is utilized by experts and professionals within their aspect of academics, and high-class courses with important digital syllabus and outline which would be reachable in all majors. Students have always deadlines to follow for completion of the assignments, yet they have no comprehensive understanding of the drawing. Therefore, more often they follow the tutorials to complete assignments in a hurry. The hand drawings also got damaged easily, and the tools available are also limited. They also have to carry tools with them all the time. The professionals also want to have graduates who are literate with technology to work fast and to compete in the highly advanced technology workplace. Many of the manufacturers, stakeholders, and contractors are welcoming for persons with digital software awareness [3].

Some results show that the people are not fully competent so they cannot use digital software properly even the whole work now depends on the software. Then, the deficiency in understanding and cooperating different digital software and also the coordination between theory courses and digital software are failing in proper interior design, which gives rise to further explore the area $[1,5]$. The improper utilization of the advanced digital software with the overwhelming reliance on them, the presence of numerous computerized instruments, and, more importantly, the hidden strong cooperation between assumed courses and configuration ventures have given an unreliable plan, that offer to raise to investigate the region further [6].

This study will cater to the demand for professional digital software in academics and also in the industry; the professional practices are required to be handled carefully and comprehensively. The training starts from the academic phase so the teachers must be conscious to fully train their students about the digital design software so they can lead in a professional race.

The study was delimited to the students of Interior Design and product design students in the final year. Only three institutions were selected for the study, named, Department of Interior Design in University of Home Economics (UHE), Department of Interior Design in Lahore College for Women University (LCWU), Department of Product and Industrial Design in University of Engineering and Technology (UET) and, all these three Universities are in Lahore, Pakistan. The target of the study is to examine the impact of DDS on interior design education and its after-effects.

The objectives are set as given below:

a). To find out the feasibility of Hand Drawing Skill (HDS) used by students of Interior Design (ID) course

b). To fund out the feasibility of Digital Design Software (DDS) used by students of Interior Design (ID) course

c). To fund out the feasibility of Digital Design Software (DDS) used in professional fields after academic qualification.

\section{Literature Review}

The literature is provided to support the evidence that the hand drawing skill (HDS) is now considered a conventional tool in the interior design profession and the hindrances of using HDS, secondly to access the researchers who investigated about the use of digital design software (DDS) in the interior design (ID) courses and the efficiency of using the software in academics and thirdly to see the impact and use of DDS in the professional fields after academic qualification.

\subsection{Need for Digital Design Software (DDS) in Educational Fields}

Hand drawing is getting obsolete in the professional market. The digital world has given a lot of software to draw and create. Just like this, it is easy for teachers to teach skills in an easier way on computer screens. The conclusion is that digital software is high in demand, but drawing skill is also not to be left because it is also in hand skill which needs no device to be drawn $[7,8]$.

Yaaqob concluded in his study that students were agreed to have digital software skills to complete their targeted drawings in time in Malaysia, particularly in community colleges [5]. It is also documented by Jared that students must have direct guidance to proficiently utilize digital technology innovation applications, for example, composing the refined software [9]. These projects give digital aptitudes in cutting edge computer and digital innovation applications that will empower employees to expect more control explicit digital-based ventures. There are numerous issues identified with the effective utilization of innovation in the classroom concerning stages, equipment, programming, etc. While these are maybe the most evident contemplations [10].

The important is to pick the accurate hardware and software programming for the class is fundamental; it is the understanding and outlook of the teacher that chooses the feasibility of advancement adding into the instructive arrangement. The two researchers Bitner and Bitner in their examination concluded that it is the significance, rather than a number, of computer or digital skill students bring to class that is commonly judicious of execution [10]. Consequently, an audit on the basic data on both HDS and DDS aptitude can be finalized. Properly, just computer self-efficacy was viewed as on a very basic level related to computer subordinate course execution [3].

Brandon and McLain-Kark covered an examination on the interior design tasks to look within HDS and DDS strategies have a critical difference. The investigation uncovered no huge contrasts among the two design techniques on the seven sections of design categories when they were applied in building up an interior arrangement. The HDS and DDS techniques were utilized adequately to create feasible design arrangements [11]. 
However, extra research analyzing the impacts of these techniques is important before suppositions can be figured regarding their effect on the design procedure. Consequently, the need of utilizing DDS helped programming in making indistinguishable products than from HDS. A large portion of correlated works, study, and research, has come about to the requirement for less complex programming or simpler plan procedure to make a drawing. The research has explored that the teachers themselves must be DDS educated before advancing and acquainting the strategies with the students [5].

\subsection{Digital Design Software: A Computer Aid as in Interior Design Course}

Designing is a pursuit to join both physical and conceptual tools and devices. The design is a process that uses a series of courses along with the physical tools, for instance, all available drafting and drawing techniques are used as instruments. A few calculated devices, for instance, the shape punctuation is used. The designers or fashioners use these conceptual tools to extract and handle the structure issue, objectively reproduce, make sense of and resolve it subsequently produce the plan thought and the physical devices are the ones to envision and understand the structure [12]. Physical tools like computers and laptops provide essentially to the affirmation of the last plan conspire. Pioneers of PC supported program, organized the product to duplicate the equipment apparatuses, for instance, pencils, paper, and paintbrush. Designing and planning demands from the designer to think ostensibly and must be innovative, along these lines visual components made during the structure method sway the designer's thinking. Design software programming goes about as a visual guide or guide through three-dimensional (3D) modeling and sketches. The design is anything but a straightforward procedure that centers around the objective, however, a netlike way that incorporates quick inputs and to be tediously drawn at their ideal focuses. For example, in a multi-story working with ordinary floor plan, progressive floor plans can be drawn by replicating the underlying arrangement and gluing at wanted focuses. Nonetheless, hand drawing or manual drafting has to be done every time for each floor plan [13].

The designers must have the courage to handle difficulties that interface of DDS that prompts the improvement of predictive results in design. A designer ought to be solution-driven however not issue driven. One may contend that DDS utilized in the plan procedure becomes viable when all the potential thoughts of the errand have been broken down to the intricate details and the best arrangement landed at; a view that outcomes in the way DDS is instructed in the division, for this situation the computer is decreased to an insignificant electronic board [14]. Nonetheless, ongoing progression in DDS makes it conceivable at the reasonable phase of the structure to the last phase of the plan procedure [15].

DDS programs are intended to have the ability to play out various complex plan tasks with minimal human exertion in a brief span which generally would require concentrated human exertion and an extensive timeframe to achieve with conventional techniques for structure, that is, manual drafting. In the customary strategy for drafting, any mistakes that should be rectified promptly a total redrafting/backtracking of the venture. For example, a spill of ink on the sheet or an adjustment in the spatial course of action of spaces on the floor plan requires redrafting of the undertaking. Interestingly planning with DDS takes into consideration the influenced segment to be adjusted without the need to redraw the whole task. DDS is helpful that considers comparable highlights in the planned venture to be tediously drawn at their ideal focuses. For example, in a multi-story working with ordinary floor plan, progressive floor plans can be drawn by replicating the underlying arrangement and gluing at wanted focuses. Nonetheless, manual drafting requires redrawing each floor plan.

\subsection{Digital Design Software (DDS) versus Creativity}

Design instructors endeavor to prepare the eyes and psyches of students to see and grasp their general surroundings with the expectation of setting up those students to turn out to be great originators, basic masterminds, and at last capable modelers". In like manner, students are relied upon to be imaginative in their quest for turning out to be modelers. Students of Architecture endeavor to accomplish a degree of expert skill. The capacity to think outwardly is an expertise that recognizes modelers from different experts [16].

The mentors for DDS have the obligation of urging students to think about how DDS can be utilized innovatively. DDS can be utilized as an augmentation of our inventive potential outcomes. Imagination can be improved using DDS in the advancement of structural structures and the consequent perception of the structure through 3D displaying, renderings, activities, and DDS generated reality [17]. The method of educating DDS in the division doesn't support the utilization of DDS at a reasonable stage. DDS is only instructed as an advanced portrayal of 2D works done through conventional structures techniques. Students are relied upon to remember all AutoCAD directions they are then given 2D drawings on a sheet to imitate the LAPTOP with the AutoCAD program.

Moreover, DDS is instructed in the detachment of other structure courses in the division. This doesn't just confine the imagination of students; however it doesn't propel the students to get familiar with the instrument. It is advised architects to be exhausted from the DDS since it could influence their innovative reasoning, the creators ought to consciously distinguish between heuristic of structure and 
heuristic of strategy. This would make a harmonious connection between the planner and the software [7].

The design process may be divided into two stages the first proposal making or concept stage where students can use software to show their ideas through bubble drawings and pictures and on working stage, they need to make 3D drawings and prototypes. The software is best to use for such drawing and visuals because if all these steps are practiced manually, it is time taking and not perfect but software handling can improve the quality of the projects. That is why all renounced institutions have added digital skills as compulsory courses especially in interior design programs [18][19][20].

\section{Research Methodology}

The purpose of the survey was to collect data on the critical problems of the use of hand drawing and the need of using DDS in Interior design subjects. This is quantitative research in which structured questionnaire was asked to the final year students in three institutions of Interior Design, 30 students were selected from each institution because to take an equal number of students in the same annual year. The curriculum of the institutions was consisted mainly of $2 \mathrm{D}$ and $3 \mathrm{D}$ images, perspective drawings, ambiance and project designing so the students were learnt both hand and digital skills to complete their projects. The questionnaire template was taken from the research work of Abdullah et. al., but several changes were made in the questionnaire according to the requirement of the study and a pilot test also confirmed useful changes for the study [3]. Twenty-four (24) items were asked about the need of digital design software in ID course and five (5) items about demography and to know about awareness about DDS were asked such as name, age, class, DDS Knowledge, Know how to use DDS, how strongly they can use DDS in their projects, how accurately they use DDS. The questionnaire used a Likert ranging from (1-5), 1 strongly agree, 2 agree, 3 neutral, 4 disagree and 5 strongly disagree. The sample was purposefully selected, based on the average strength of the final year students in selected ID institutions, 30 students were selected from each department and a total was 90 . The names of selected institutions were Department of Interior Design, University of Home Economics (UHE), Institute of Design and Visual Arts, Lahore College for Women University (LCWU), Department of Product and Industrial Design, University of Engineering and Technology (UET) in Lahore, Pakistan. The two institutions were purely teaching ID course but the third one was involved in product design which is also a branch of Interior Design (ID), so it was also considered under ID institutions. These institutions were selected because all the students were computer literate and they were taught and they knew how to use digital design software such as Auto CAD, 3D Max, Adobe Photoshop,
Sketch-up in general, even then, the question we're asked about their efficiency in using DDS skill.

\section{Analysis and Results}

The analysis and the results, as also stated by Abdullah et. al., [3] three variables have been indicated which are: the difficulties in hand drawing class, the easiness of handling DDS, and the possibilities with DDS after educational years [3]. These three variables headed to the evaluation procedure of the demand of DDS in the ID course. The respondents which were selected among three institutions were mostly females because the two institutions were only catering female students and one with mixed gender, from a total of 90 students 30 from each department or institution, 68 (75.6\%) were female students and $22(24.4 \%)$ were male.

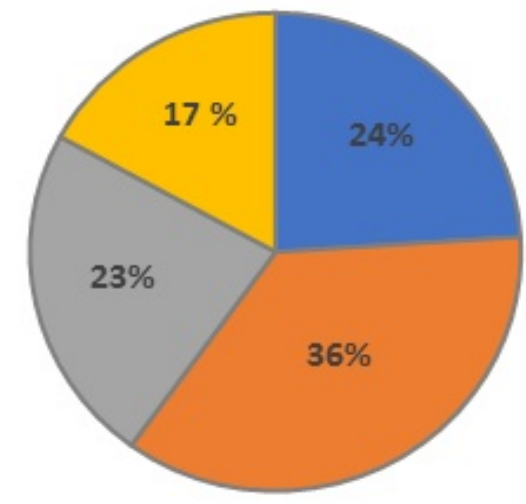

=excellent aGood aAverage aPoor

Figure 1. Evaluation of DDS Skills in ID students

Figure 1 is the evaluation chart of DDS skill in the students of ID course, ranging from excellent to poor. The total of $36 \%$ students were good in the DDS skill, $24 \%$ were excellent, $23 \%$ were average and only $17 \%$ of students considered themselves poor in DDS skill. It is concluded that most of the students were having command on the DDS skill.

Figure 2 shows that when students were asked about the error rate in their final drawing or product outcome, $32 \%$ answered they make error rare, $23 \%$ answered that they make drawings usually accurate, $21 \%$ answered that they can make accurate drawings, $17 \%$ answered that they make passable errors and only 7\% answered to make frequent errors so the conclusion is that most of the students can make drawing with accuracy. 


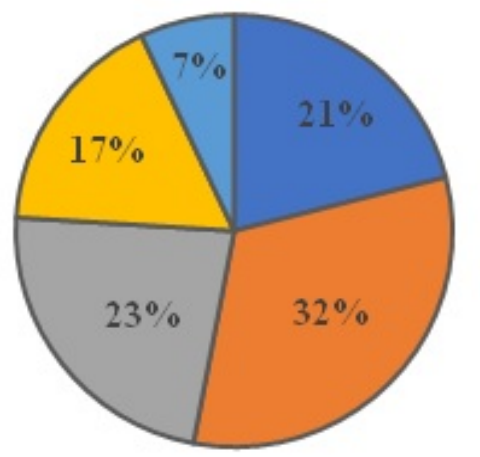

\section{Accurate 口Usually Accurate $\square$ Frequent Errors \\ $\square$ Error Rate 口Passable}

Figure 2. Use of DDS and Error Rate in Product Outcome.

Table 1. Convenience of Hand Drawing Skill (HDS) for ID students

\begin{tabular}{|c|c|c|c|}
\hline No. & $\begin{array}{l}\text { Statements related to Convenience } \\
\text { of HDS for ID Students }\end{array}$ & Mean & SD \\
\hline 1 & $\begin{array}{l}\text { The hand drawing class is not the } \\
\text { most exciting class that I would } \\
\text { love to join }\end{array}$ & 3.18 & 1.03 \\
\hline 2 & $\begin{array}{l}\text { I do not have the abundant skill to } \\
\text { complete my drawing manually in } \\
\text { the interior design }\end{array}$ & 2.48 & 1.32 \\
\hline 3 & $\begin{array}{l}\text { I do not have ample time to finish } \\
\text { my drawing by hand in an interior } \\
\text { design course }\end{array}$ & 2.75 & 0.99 \\
\hline 4 & $\begin{array}{l}\text { I cannot imagine clearly to draw } \\
\text { by hand in an interior design } \\
\text { course }\end{array}$ & 3.31 & 0.97 \\
\hline 5 & $\begin{array}{l}\text { I think hand drawing is an } \\
\text { overload in my course }\end{array}$ & 2.03 & 1.38 \\
\hline 6 & Hand drawing takes lot of time & 1.94 & 1.13 \\
\hline 7 & $\begin{array}{l}\text { I get disturbed easily in hand } \\
\text { drawing as I cannot draw like an } \\
\text { expert teacher }\end{array}$ & 1.85 & 0.55 \\
\hline 8 & $\begin{array}{l}\text { I think hand drawing is a } \\
\text { conventional method for final } \\
\text { presentations }\end{array}$ & 2.27 & 0.83 \\
\hline
\end{tabular}

Table 1 shows the convenience of HDS for ID students. The mean ranges from 1.85 to 3.31 . The highest mean is 3.31 which means most respondents neither agree nor disagree that to imagine a design through hand drawing is convenient for them, the least SD for the same statement is 0.97 which proved that respondents strongly agree with item 4 that most of the students chose the same answer. Most of the statements resulted in the mean of 2 which concludes that most of the students agree to not find HDS convenient in ID course and SD values also supported the results which range between 0.55 to 1.38 .
Table 2. Convenience of Digital Design Skill (DDS) for ID students.

\begin{tabular}{|c|c|c|c|}
\hline No. & $\begin{array}{c}\text { Need for DDS in ID Profession along } \\
\text { with academic qualification }\end{array}$ & Mean & SD \\
\hline 1 & $\begin{array}{c}\text { I like to use CAD software in the } \\
\text { interior design course }\end{array}$ & 2.75 & 1.28 \\
\hline 2 & $\begin{array}{c}\text { Using digital design software is easier } \\
\text { than drawing by hand }\end{array}$ & 2.21 & 1.39 \\
\hline 3 & $\begin{array}{c}\text { Using digital design software is faster } \\
\text { than drawing by hand }\end{array}$ & 2.75 & 0.98 \\
\hline 4 & $\begin{array}{c}\text { The assignment made by using digital } \\
\text { design software is easier to present than } \\
\text { hand drawing }\end{array}$ & 2.24 & 1.05 \\
\hline 5 & $\begin{array}{c}\text { I am confident to present my drawings } \\
\text { by using software instead of hand } \\
\text { drawing. }\end{array}$ & 2.03 & 1.38 \\
\hline 6 & $\begin{array}{c}\text { I consider digital design software } \\
\text { cost-effective }\end{array}$ & 1.94 & 1.13 \\
\hline 7 & $\begin{array}{c}\text { My institution provides appropriate } \\
\text { facility in terms of digital lab \& its } \\
\text { software }\end{array}$ & 1.85 & 0.55 \\
\hline 11 & $\begin{array}{c}\text { I can practice and approach the source } \\
\text { during class hours }\end{array}$ & 2.07 & 0.98 \\
\hline 12 & $\begin{array}{c}\text { I have design software installed on } \\
\text { laptop as a tool in my hand }\end{array}$ & 2.1 & 0.42 \\
\hline $\begin{array}{c}\text { I consider digital design software } \\
\text { innovative in the design process of the } \\
\text { interior design course }\end{array}$ & 2.34 & 0.85 \\
\hline in digital software & 2.1 & 1.38 \\
\hline
\end{tabular}

Table 2 shows the analysis of the convenience of using DDS by ID students. The mean ranges from 1.85 to 2.75 which cleared that the students feel convenient to use DDS. Item 6,7 and 10 show low $\mathrm{SD}, 1.13,0.55$, and 0.42 respectively, which gives a clear understanding that most of the respondents agree to have the same answers which indicate to have their convenience in using DDS in ID course. Other than this SD ranges from 0.42 to 1.38 which also supports the results and concluded that student's convenience is in using DDS. But the students want their tutors to have more training in DDS with a mean value of 2.1 and SD 1.38 .

Table 3. Need for DDS in ID Profession along with qualification

\begin{tabular}{|c|c|c|c|}
\hline No. & $\begin{array}{c}\text { Statements related to Convenience of } \\
\text { HDS for ID Students }\end{array}$ & Mean & SD \\
\hline 1 & $\begin{array}{l}\text { I understand the demand for interior } \\
\text { designing as a profession }\end{array}$ & 2.34 & 1.02 \\
\hline 2 & $\begin{array}{l}\text { Most organizations need a person } \\
\text { aware of digital design software }\end{array}$ & 2.21 & 1.05 \\
\hline 3 & $\begin{array}{c}\text { My seniors got jobs easily because } \\
\text { they have advanced knowledge in } \\
\text { design software }\end{array}$ & 1.78 & 1.20 \\
\hline 4 & $\begin{array}{l}\text { I can have my own company since I } \\
\text { know how to use digital design } \\
\text { software in interior design }\end{array}$ & 1.93 & 1.13 \\
\hline 5 & $\begin{array}{l}\text { Most organizations in interior design } \\
\text { fieldwork on digital design software }\end{array}$ & 2.5 & 0.89 \\
\hline
\end{tabular}


Table 3 shows the analysis of the need for DDS in professional fields after the completion of academic qualification. The mean ranges from 1.78 to 2.5 which concludes that students are aware of the need for DDS in professional fields along with their academic qualification. Because they were aware that whether they have to work on the conceptual stage or on implementation stage they can have more proficiency though software. The SD is low in all the items, which ranges from 0.89 to 1.20 , which also supports the answers. This concludes that the students clearly understand the need for DDS in professional fields after their academics.

\section{Discussion and Conclusions}

The study revealed the revolution in the field of education through the digital world of software [1]. The study was conducted on the interior design students in three renowned institutions in Pakistan. Even several types of research are being done on the need for digital design skills in many fields but interior design is purely considered a filed involved with imagination, design, and drawings. The educational institutions are getting well equipped with the latest digital tools [6] in developing countries so it is also worth to investigate the gaps and progress in the digital world. Many researchers found that digital design software is now high in demand in institutions [7]. The results of the study have showed that students were not accepting hand-drawing skills effective and comprehensive when they have to make drawings and projects whether it is only to show creativity or to complete the projects on time or to compete in the professional field. The students also want digital design software because not only of the convenient use but also of ready to use skill and cost-effective [5, 9]. The revolutionary techniques of digital software also increase creativity and innovation to the design $[5,10]$. The advanced use of digital design software also replaced the traditional use of pencil and paper $[10,13,15]$.

The students consider DDS more effective than HDS and they know how to accurately use DDS in interior design. The most effective is the industrial use of the software. The students also wish that their tutors must have more training about DDS which is also stressed by [7]. The study, which was conducted on the students of ID institutions in Lahore, Pakistan highlighted that hand drawing is not convenient for the students when they have learned DDS skills and the need for DDS in Professions after academic qualification. The results also show that the ID students can make projects faster and easier than hand drawings and that drawings can be presented at everyplace all the time. Finally, the students become more marketable to be hired after colleges.

The findings of the study conclude that the drawings are must in interior design courses, the curriculum of the institutions consisted mainly of $2 \mathrm{D}$ and $3 \mathrm{D}$ images, perspective drawings, ambiance and project designing so it is requirement of the course to learn DDS along with HDS. HDS require more time to complete a project, needs to make again if got wrong and sometimes cannot represent perfect ideas in imagination. DDS is modern way for presentation of drawings, easier to use and present, it is fast and gives perfection to drawings, it is cost effective because it needs less time than HDS. The other benefit is it can be altered as many times as required. It requires no equipment but a laptop, so it is handy and portable to use while sitting anywhere.

\section{Acknowledgements}

The Authors are thankful to the selected institutions of the universities and especially the students for providing useful information. Special thanks are also presented to $S$. A. Abdullah, A. Yaakub and Z. Wahil whose methodology and work procedure were followed for the study.

\section{REFERENCES}

[1] R. Al-Matarneh, I. Fethi. Assessing the Impact of CAAD Design Tool on Architectural Design Education. Malaysian Online Journal of Educational Technology. Vol. 5, No. 1, $1-20,2017$.

[2] M. Arif Kamal, M. Saquib, Effective Learning through Integrated Automation in Architectural Education: A model Framework, Architecture Research, Architecture Research, Vol. 5 No. 4, pp. 121-124.Scientific and Academic Publishing, USA, 2005.

[3] S. A. Abdullah, A. Yaakub, \& Z. Wahil. Evaluating students' needs in using computer-aided software in a landscape design course. Procedia-Social and Behavioral Sciences, Vol. 195, No. 828-836. 2015.

[4] D. Monk, D. Philip, P. Don, H. Peter, \& Y. Paul. Meeting the Needs of CALS Students for Computing Capabilities. Final Report of the Ad Hoc Committee on College of Agriculture and Life Sciences Student Computing Competencies. Educational Resources Information Center (online). 1996. http://eric.ed.gov/?id=ED40290

[5] Y. E. Kalay. The Impact of Information Technology on Architectural Education in the 21st Century. In 1st International Conference on Critical Digital: What Matters, 3-6.2008.

[6] T. KUTLUCA. The Effect on Students' Achievements of Computer Assisted Instruction Designed for Quadratic Functions. Journal of Research, Vol. 13, No. 2, 347-358. 2019.

[7] O. O. Ogunsote. Curricular Anatomy of the CAD Proficient Architecture Graduate in Nigeria (Doctoral dissertation, Association of Architectural Educators in Nigeria (AARCHES) Theme: The Challenges of Architectural Education in the 21st Century Sub-Theme: The Impact of Information and Communications Technology (ICT) on 
Architectural Education Held at the Engineering Lecture Theatre, Federal University of Technology). 2006.

[8] J. Keengwe. Handbook of research on active learning and the flipped classroom model in the digital age. IGI Global. 2015.

[9] J.R. Rollins. College and Career Ready through Personalized Learning: Business and Industry Perspective of the Don Tyson School of Innovation. 2017.

[10] N. Bitner. \& J. O. E. Bitner. Integrating technology into the classroom: Eight keys to success. Journal of technology and teacher education, Vol. 10, No. 1, 95-100, 2002.

[11] L. Brandon, \& J. McLain-Kark. Effects of Hand-Drawing and $\mathrm{CAD}$ techniques on design development: A comparison of design merit ratings. Journal of Interior Design, Vol. 27, No. 2, 26-34. 2001.

[12] M. S. Hatem, H. A. Ramadan, \& D. C. Neagu. E-learning based on context oriented semantic web. Journal of Computer Science, Vol.1, No. 4, 500-504. 2005

[13] S. Asut. Rethinking the Creative Architectural Design in the Digital Culture. First International Conference on Critical Digital: What Matter(s)? 229-234, 2009.

[14] S. Benton. Mediating between Architectural Design Ideation and Development through Digital Technology. 253-260,
2007.

[15] S. N. M. Mohamad, S. Sazilah, A. M. S. Mohd, B. Norasiken, \& K. M. S. Linda. The Effectiveness of Online Multiple Intelligences Teaching Tools (On-MITT) on Improving Lecturers' Motivation. International Journal WIT Transactions on Information and Communication Technologies for Education, Vol. 58 No. 1, 491-498. 2014.

[16] G. Proctor. CADD Curriculum-The Issue of Visual Acuity. Education \& Curricula - 07 The Ideal Digital Design Curriculum, Department of Architecture, California State Polytechnic University Pomona, 192-200, 2001.

[17] K. Rex, \& R. M. Roth. The relationship of computer experience and computer self-efficacy to performance in introductory computer literacy courses. Journal of research on computing in education, Vol. 31, No. 1, 14-24. 1998.

[18] F. D. Ching, \& C. Binggeli. Interior design illustrated. John Wiley \& Sons. 2018.

[19] L. Brandon, \& J. McLain-Kark. Effects of Hand-Drawing and CAD techniques on design development: A comparison of design merit ratings. Journal of Interior Design, Vol. 27, No. 2, 26-34. 2001.

[20] O. Berge. Rethinking digital literacy in Nordic school curricula. Nordic Journal of Digital Literacy. Vol. 12, No. 01-02, 5-7, 2017. 